\title{
Vaginal Calculi in the Eastern North Atlantic Common Dolphins Delphinus Delphis, Induction Mechanisms and Possible Effects on Fecundity
}

\author{
Willy Dabin ${ }^{1 *}$, Bastien Rochowski ${ }^{1}$, Michel Daudon ${ }^{2}$ and Vincent Ridoux ${ }^{1,3}$ \\ ${ }^{1}$ Observatoire PELAGIS, UMS 3462 ULR-CNRS, La Rochelle Université, La Rochelle, France, ${ }^{2}$ Hôpital Necker, Service \\ de Biochimie, Paris, France, ${ }^{3}$ Centre d'Etudes Biologiques de Chizé, UMR 7372, ULR-CNRS, Université de La Rochelle, \\ La Rochelle, France
}

\section{OPEN ACCESS}

Edited by:

Debra Lee Miller,

The University of Tennessee,

Knoxville, United States

Reviewed by:

Ashley Reeves,

University of Tennessee, Knoxville,

United States

Lonneke Liza IJsseldijk,

Utrecht University, Netherlands

*Correspondence:

Willy Dabin

wdabin@univ-Ir.fr

Specialty section:

This article was submitted to

Marine Megafauna,

a section of the journal

Frontiers in Marine Science

Received: 10 July 2020

Accepted: 26 May 2021

Published: 08 July 2021

Citation:

Dabin W, Rochowski B,

Daudon M and Ridoux V (2021)

Vaginal Calculi in the Eastern North Atlantic Common Dolphins Delphinus

Delphis, Induction Mechanisms and Possible Effects on Fecundity.

Front. Mar. Sci. 8:582034.

doi: 10.3389/fmars.2021.582034
The proper management of cetacean populations requires life history and demographic parameters to be estimated at population level. In this study we focus on a reproductive pathology that has the potential to alter reproductive rate: the vaginal calculi or stones. The present work documents vaginal calculi prevalence and structure in the eastern North Atlantic common dolphin Delphinus delphis in order to infer their likely mechanisms of induction and possible effects on fecundity. The work is based on routine examinations and necropsies of stranded marine mammals reported by the French stranding scheme from 1972 to 2012. Vaginal calculi were described and measured, and their composition was analyzed by Fourrier-Transformed Infra-Red (FTIR) spectroscopy. Necropsies and reproductive tract examinations were performed on 435 female common dolphins since 1972 along the French coasts, of which 14 showed vaginal calculi, representing 3.2\% of the examined females. All females with calculi were older than 7 , and there was no relationship of calculus size with age. Histopathology revealed lesions due to an inflammatory response to the presence of the calculi: chronicle vaginitis, variable endometritis and cystitis. Calculus size varied from 1 to $21 \mathrm{~cm}$ in maximum dimension and 4-1,460 $\mathrm{g}$ in mass. Their internal structure was homogeneous, particularly due to the absence of core material, hence corresponding to the definition of primary calculi. All calculus spectra showed almost identical compositions, with struvite (magnesium ammonium phosphate hexahydrate) representing on average $87 \%$ of calculus mass. Dysfunction of the uro-genital tract, such as vesico-vaginal fistulae, would be the likely initial pathological condition that led to the formation of these stones. Both the initial chemical condition in the vagina and the resulting formation of a calculi are obstacles to successful reproduction.

Keywords: pathology, fecundity, stranding, common dolphin, demographic, spectroscopy

\section{INTRODUCTION}

The proper management of cetacean populations requires life history and demographic parameters to be estimated at population level. In addition to reproductive parameters sensu stricto, pathologies of the genital tract can be relevant as well, in that they can be associated with sterility (Boyd et al., 1999). In this study we focus on a reproductive pathology that has the potential to alter reproductive rate: the vaginal calculi or vaginal stones. 
Vaginal stones have been well documented in mammals like Guinea pigs, moles, bats and primates, including man (Harrison, 1969; Raghavaiah and Devi, 1980; Oguzkurt et al., 2009). In human medicine, $82 \%$ of vaginal calculi are due to fistulas resulting from gynecologic surgery, $8 \%$ to obstetric procedures, $6 \%$ to pelvic radiotherapy, and $4 \%$ to trauma (Lee et al., 1988; Singhal et al., 2007). The general conditions described as contributing to calculi induction are cystic lesions due to an obstructed genital tract or to the presence of embryological remnants. Reflux of urine into the vagina during voiding may mimic a cystic lesion. Solid lesions are uncommon and are usually fibroids or neurofibromas. Malignant lesions usually occur in elderly patients and account for only 1-2\% of gynecological malignancies. Most malignancies are usually squamous cell carcinomas, although adenocarcinomas and melanomas do occur. Younger patients may get rhabdomyosarcoma (Allan et al., 2011).

These stones may be primary or secondary. Primary stones are formed in the vagina due to the deposition of urinary salts as a result of continuous urinary leakage into the vagina resulting from vesicovaginal fistulae and concomitant bacterial infections (Hildebrand, 1987). The internal structure of primary stones is homogeneous without foreign bodies in the nucleus, and its section appears smooth. The structure is mainly made of struvite (magnesium-ammonium-phosphate). A secondary vaginal stone is formed around a foreign body in the vagina and results from the reaction of the organism involving hormonal and calcium mobilization (Warner et al., 1979). Secondary stones are extremely polymorphic and show internal organization with a nucleus composed of foreign bodies secondarily embedded in crystals that are similar in composition to the apatite of dental calculus. Both primary and secondary vaginal calculi can occur as single or multiple stones.

Vaginal calculi are reported to alter reproductive parameters. Firstly, calculi over $20 \mathrm{ml}$ would induce mating failure in dolphins by reproductive tract occlusion (Essapian, 1961). Secondly, the chemical environment required for crystal formation would also lead to sterility (McFee and Osborne, 2004). However, this harmful chemical environment is only permanent in the case of physiological dysfunction associated with primary stones, whereas these conditions stop in the case of secondary stones when the foreign bodies are expulsed or isolated.

Many cases of vaginal stones were reported in marine mammals. Several delphinid species have been reported to display vaginal stones: the dusky Lagenorhynchus obscursus (Van Bressem et al., 2000), Pacific white-sided L. obliquidens (Harrison, 1969), pan-tropical spotted Stenella attenuata (Sawyer and Walker, 1977), bottlenose Tursiops truncatus (McFee and Osborne, 2004), and common Delphinus delphis (Sawyer and Walker, 1977; Bernirschke et al., 1984; Woodhouse and Rennie, 1991) dolphins. However, the prevalence of this condition and its potential effect on reproductive outputs at population level are unknown.

The goal of the present work was to address the issue of vaginal calculi prevalence and structure and infer their likely mechanisms of induction and possible effects on fecundity. To do this, we described the prevalence of this pathological condition in the eastern North Atlantic common dolphin and its
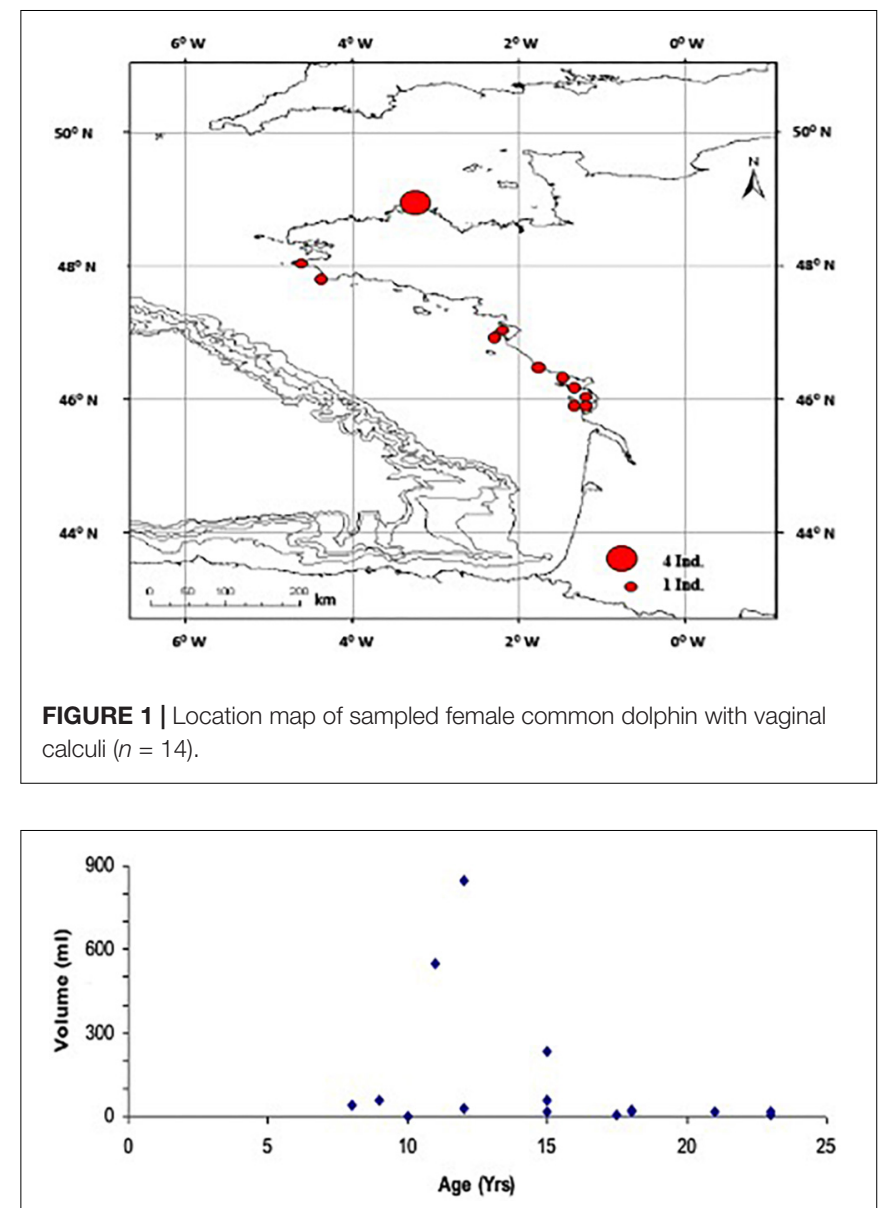

FIGURE 2 | Vaginal calculus size as a function of dolphin age $(n=14)$.

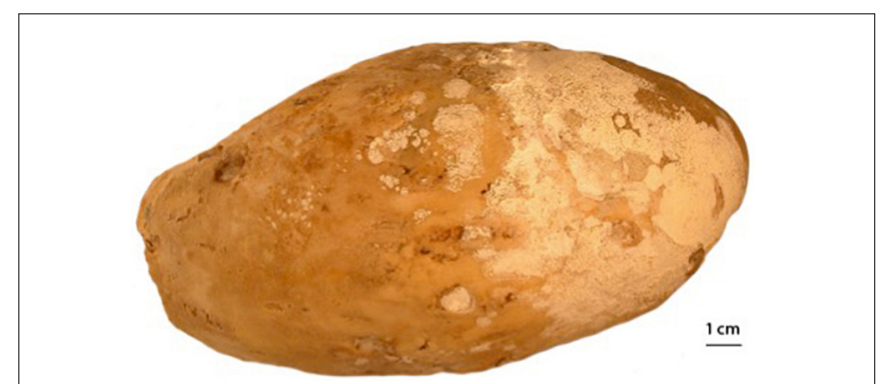

FIGURE 3 | Largest vaginal calculi observed (collection number 10202178).

relation with age and reproductive status. Besides, we analyzed composition of calculi by using Fourrier Transformed InfraRed (FTIR) spectroscopy. In small cetaceans, the examination of stranding events represents a major source of samples from which health condition and reproductive parameters can be estimated. The present work is based on routine examinations and necropsies of stranded marine mammals reported by the French stranding scheme from 1972 to 2012. In a second step, all calculi found during necropsies were described in terms of size, internal structure and chemical composition. 
TABLE 1 | Veterinary and histopathology appearance $(n=14)$.

\begin{tabular}{|c|c|c|c|c|c|c|c|c|}
\hline \multirow{2}{*}{$\begin{array}{l}\text { Calculus } \\
\#\end{array}$} & \multirow{2}{*}{$\begin{array}{c}\text { Stranding } \\
\text { Date }\end{array}$} & \multirow[t]{2}{*}{ Age } & \multirow[t]{2}{*}{ Nature } & \multicolumn{3}{|c|}{ Diameters } & \multirow{2}{*}{$\begin{array}{c}\text { Mass } \\
\text { (g) }\end{array}$} & \multirow{2}{*}{$\begin{array}{c}\text { Volume } \\
\text { (ml) }\end{array}$} \\
\hline & & & & $\begin{array}{l}\text { D1 } \\
\text { (cm) }\end{array}$ & $\begin{array}{c}\text { D2 } \\
(\mathrm{cm})\end{array}$ & $\begin{array}{c}\text { D3 } \\
\text { (cm) }\end{array}$ & & \\
\hline 1675 & $13 / 02 / 84$ & 10 & Single & 2.6 & 2.1 & 1.2 & 4 & 2 \\
\hline 1760 & 14/04/85 & 17,5 & Single & 4.3 & 3.1 & 1.9 & 12 & 8 \\
\hline 10202157 & 19/02/02 & 21 & Single & 5.9 & 4.2 & 1.5 & 21 & 16 \\
\hline \multirow[t]{2}{*}{1265} & 07/08/81 & 24 & Multiple* & 4.8 & 1.9 & 1.6 & 7 & 4 \\
\hline & & & & 5.2 & 3.2 & 1.9 & 24 & 16 \\
\hline 1630 & $25 / 01 / 84$ & 15 & Single & 6.7 & 4 & 1.3 & 28 & 18 \\
\hline 1797 & 24/01/86 & 18 & Multiple $^{\star \star}$ & - & - & - & 31 & 19 \\
\hline 1709 & $26 / 11 / 84$ & 15 & Single & 6.2 & 4.2 & 2.1 & 37 & 25 \\
\hline 2131 & 06/01/89 & 15 & Single & 7 & 5.3 & 3.4 & 44 & 28 \\
\hline 10202165 & 19/02/02 & 8 & Single & 6.4 & 4 & 2.6 & 41 & 42 \\
\hline 1600 & 11/09/85 & 12 & Single & 8.9 & 4.8 & 3.9 & 88 & 61 \\
\hline 1807 & 03/03/86 & 9 & Single & 8.9 & 4.8 & 3.9 & 50 & 61 \\
\hline 9604023 & $16 / 04 / 96$ & 24 & Single & 11.8 & 7.0 & 6.1 & 348 & 236 \\
\hline 10202169 & 19/02/02 & 11 & Single & 16.8 & 8.7 & 7.5 & 875 & 551 \\
\hline 10202178 & 19/02/02 & 12 & Single & 21.1 & 9.4 & 8.1 & 1,460 & 845 \\
\hline
\end{tabular}

\section{MATERIALS AND METHODS}

\section{Origin of the Samples}

Biological material was made available by the French stranding scheme which monitors and examines marine mammal strandings since the early 1970's. The network is composed of field correspondents trained to use standard examination protocols (Kuiken and Hartmann, 1991; Jauniaux et al., 2005), under supervision by Observatoire PELAGIS, at the University of La Rochelle. Yearly reports of stranding events are made available online at http://observatoire-pelagis.cnrs.fr/publications/rapports/.

\section{Age Determination}

Tooth preparation was adapted from the protocol described by Lockyer (1995). Teeth were immersed in a decalcifying agent $\left(\right.$ DC3 $^{\odot}$ Labonord, Z.I. de Templemars, f-59175 Templemars, France) before sectioning and staining in toluidin blue (Martoja and Martoja, 1967) and then washed overnight in running tap water. Sections were mounted in a synthetic medium (Isomount Labonord ${ }^{\circledR}$ ) and examined under a stereomicroscope with transmitted polarized light (Olympus ${ }^{\circledast}$ BH2, Olympus Optical Co., Ltd.). Growth layer groups (glg) were counted, assuming that one glg equals one year (Gurevich et al., 1980; Perrin and Myrick, 1980; Klevezal, 1996). Three independent readings were done for each tooth section (Hohn and Fernandez, 1999). All readings were recorded to the nearest whole year and age was expressed as mean for each individual.

\section{Individual Reproductive Status and Ovarian Characteristics}

Individual reproductive status was determined by the examination of the entire reproductive tracts on the basis of the criteria described and illustrated by Collet and Harrison (1981). All Corpus Albicans (CAs) and Corpus Luteum (CLs) were counted and measured in the entire ovaries (Perrin and Donovan, 1984). Females were categorized as "immature" when they had no CA, as "resting mature" when they had at least one CA and showed no sign of gestation or lactation (no CL, no fetus, no milk in the mammary gland, no expanded uterine horn), as "pregnant" when a CL was present and a fetus was found, as "lactating" when milk was found in mammary gland. Vaginal tissue was fixed in buffered formaline and processed for histopathological assessment and calculi were collected and dry stored (Perrin and Donovan, 1984).

\section{Calculus Morphometrics}

Firstly, calculi were measured (Mitutoyo CD-15DC; $0.01 \mathrm{~mm}$ ), weighed (Precisa 300C; $0.01 \mathrm{~g}$ ) and their volume determined by water displacement in a graduated cylinder. Secondly, shape,

TABLE 2 | Morphometric measurements $(\mathrm{mm})$ and microscopic observations $(n=14)$.

\begin{tabular}{|c|c|c|c|c|c|c|c|}
\hline $\begin{array}{l}\text { Calculus collection } \\
\text { number }\end{array}$ & $\begin{array}{c}\text { Left ovary } \\
\text { scars }\end{array}$ & Right ovary scars & Uterin horn & Endometrial & Vagina & Bladder & Cyst location \\
\hline 1265 & 14 & 4 & Edematous stroma & - & Chronic vaginitis & - & Uterin horne \\
\hline 1600 & 0 & 1 & Chronicle endometritis & Edematous propria & Chronic vaginitis & & - \\
\hline 1630 & 15 & 4 & - & Chronicle endometritis & Chronic vaginitis & Cyst & - \\
\hline 1675 & - & - & - & - & - & - & - \\
\hline 1709 & 3 & 0 & Endometritis & Superficial chronicle endometritis & Acute vaginitis & Cyst & Left ovary surface \\
\hline 1760 & $7-9$ & 13 & Endometritis & Chronicle endometritis & Chronic vaginitis & - & - \\
\hline 1797 & 13 & 8 & - & - & Chronic vaginitis & - & - \\
\hline 1807 & 15 & 10 & Moderate endometritis & - & Chronic vaginitis & - & - \\
\hline 2131 & - & - & - & - & - & - & - \\
\hline 9604023 & - & - & Mild endometritis & Mild endometritis & Chronic vaginitis & - & - \\
\hline 10202157 & 14 & 4 & Mild endometritis & Mild endometritis & Chronic vaginitis & - & Left ovary \\
\hline 10202165 & 13 & 7 & Mild endometritis & Mild endometritis & Chronic vaginitis & - & Left ovary \\
\hline 10202169 & - & 3 & Mild endometritis & Mild endometritis & Chronic vaginitis & - & Left ovary \\
\hline 10202178 & 22 & 4 & Endometritis & Endometritis & Chronic vaginitis & - & Left ovary \\
\hline
\end{tabular}


surface aspect and sections were described both macroscopically and microscopically. Polarized microscope was used in order to describe crystal structures (Olympus BH2, Olympus ${ }^{\circledR}$ Optical Co., Ltd.).

\section{Chemical Composition}

The composition of each calculus was analyzed by Fourier Transformed InfraRed spectroscopy (FTIR). This technique is based on the absorption of infrared radiation by calculi powder added with potassium bromure matrix in excess. Every individual spectrum was compared with reference spectra to identify the main components (Maurice-Estepa et al., 2000). The quantitative composition of each individual female spectrum was calculated from surface area of peaks (Kuzmanovski et al., 2003).

\section{RESULTS}

\section{General}

Necropsies and reproductive tract examinations were performed on 435 female common dolphins since 1972 along the French coasts, of which 14 showed vaginal calculi, representing $3.2 \%$ of the examined females. They were found along the coasts of the Bay of Biscay $(n=10)$ and the western Channel coasts $(n=4)$ (Figure 1). As many as 12 of these individuals were reported during the winter to early spring (from January to April).

Only one calculus was present at a time in most cases except in three females where multiple stones were found. All females with calculi were older than 7 , and there was no relationship between calculus volume and age (Figure 2). Smaller calculi were rather polymorphic in shape, but larger ones all tended to develop an ellipsoid shape (Figure 3).

\section{Reproductive Tract Examination and Histopathology}

The reproductive tract examinations revealed that all females with vaginal calculi were resting mature individuals as they all showed ripe follicles or CA on the ovaries (Table 1). None of these females were pregnant, but ten of the eleven females for which ovaries were examined showed active CL suggesting that ovulation had occurred recently. CA counts were about twice higher on the left ovary $(10.6 \pm 5.3)$ than on the right one $(5.7 \pm 4.0)$. Histopathology revealed lesions due to an inflammatory response to the presence of the calculi: chronic vaginitis, variable endometritis and cystitis (Table 1). Finally, none of the females were lactating.

\section{Description of Calculi}

The morphometric analysis shows a great variability in calculus size (1-21 cm maximum dimension) and mass (4-1,460 g; Table 2). Microscopically, all calculi had a smooth surface and showed no specific internal organization particularly due to the absence of core material.

\section{Identification of Main Components by FTIR Spectroscopy}

The 14 vaginal calculi were analyzed by FTIR spectroscopy. All calculus spectra (e.g., Figure 4) showed almost identical

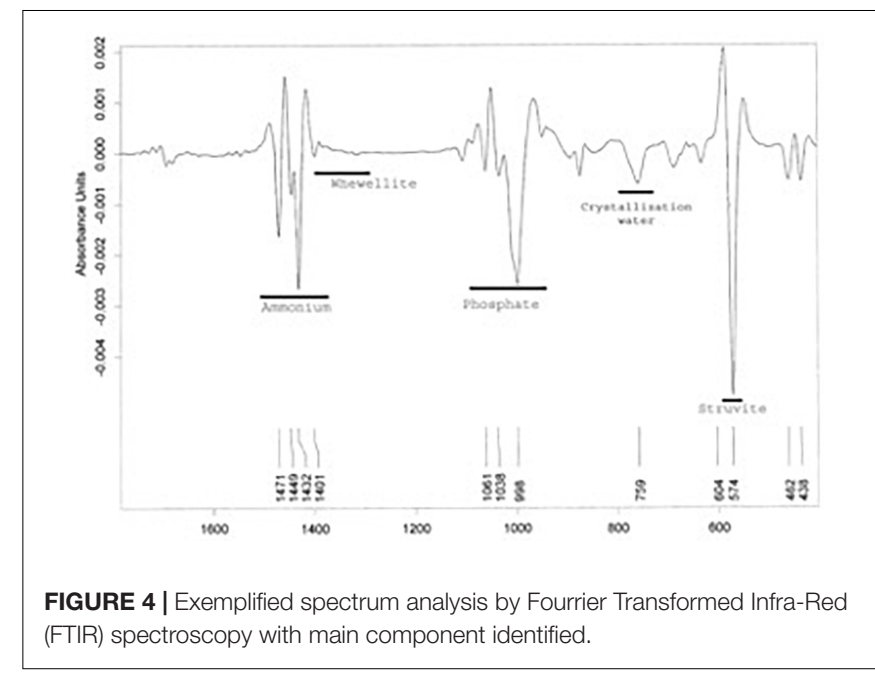

TABLE 3 | Component proportion of Vaginal calculi as revealed by FTIR spectroscopy $(n=14)$.

\begin{tabular}{lccc}
\hline Components & Occurrence $(\boldsymbol{n}=\mathbf{1 4})$ & Average crystal\% & Range \\
\hline Struvite & 14 & 87.7 & $84.5-90.9$ \\
Dittmarite & 8 & 6.3 & $4.6-8$ \\
Proteins & 14 & 3.6 & $3.1-4.1$ \\
Carbapatite & 14 & 3.3 & $2.3-4.3$ \\
Whewellite & 11 & 1.4 & $0.9-1.9$ \\
Weddellite & 3 & 1 & - \\
Urate acid ammonium & 3 & 1 & - \\
\hline
\end{tabular}

compositions. All calculi were composed of struvite (magnesium ammonium phosphate hexahydrate), calcium carbonate, whewellite, ammonium, and phosphate (Table 3). Struvite represented on average $87 \%$ of calculus mass (Table 3 ).

\section{DISCUSSION}

Vaginal calculi were only found in resting mature females with otherwise apparently functional reproductive tracts. This cannot be attributed to insufficient scrutiny during examination, because from January to April, the period when most of the sample set came from, pregnant females normally show large fetuses that cannot readily be overlooked at necropsy.

Furthermore ten out of eleven of the females examined for reproductive status had a CL on one ovary, showing that an ovulation took place recently. This proportion of ovulating females is much higher than the average figure previously reported for the Bay of Biscay population of common dolphins (39\% of mature females have a CL on one ovary, Dabin et al., 2008) and would suggest that females with vaginal calculi had higher ovulation rates than mature females with no vaginal stone, presumably because they can neither become pregnant nor lactate and therefore would stay in hormonal conditions favorable to repeated ovulation.

Vaginal calculi were extremely variable in size inrespective of the individual's age. Their internal structure was homogeneous with no core material. All calculi had a similar composition 
mainly made of struvite. They all can be considered as primary vaginal stones as defined by Hildebrand (1987).

The chemical conditions associated with calculus crystallization can be inferred from the compositions revealed by FTIR spectroscopy. High ammoniac concentration, alkaline urine, supersaturated urine with important concentration of magnesium ammonium phosphate are the likely conditions for the formation of these primary calculus (Warner et al., 1979). Continuous urinary leakage into the vagina caused by vesico-vaginal cysts and fistulae, associated with a bacteriological infection with ureasic bacteria resulting in increased ammonium concentration in the vagina are the initial pathological conditions required for struvite calculi to form (Hildebrand, 1987).

In a previous case in captivity, calculi were detected using echography and obstructed successful copulation (Essapian, 1961). These calculi were smaller than the calculi found in the common dolphin described here. Therefore, comparing to Essapian's findings, 12 individuals of the present study would be physically unable to successfully copulate as a result of genital tract obstruction. In addition to this mechanical effect on reproduction, fistulae and chemical conditions required for calculi crystallization would also be sufficient to cause sterility even before any calculus would eventually develop (McFee and Osborne, 2004).

In the present common dolphin sample set, $3.2 \%$ of all examined females had vaginal stones. Calculi were only found in mature females. Considering that the chemical environment leading to the formation of vaginal stones would prevent fertilization even before stone formation, this figure is likely an underestimation of the proportion of females made infertile because of this initial dysfunctional condition of the urogenital tract. A higher ovulation rate in females with calculi suggested by the higher proportion of females with a CL would result from their inability to become pregnant and thereafter lactating.

A closer systematic examination of uro-genital tract should be conducted on all stranded common dolphin females, notably to look at possible vesico-vaginal fistulae even in the absence of fully developed vaginal stones, in order to better estimate the proportion of infertile females among the adult population.

\section{DATA AVAILABILITY STATEMENT}

The raw data supporting the conclusions of this article will be made available by the authors, without undue reservation.

\section{REFERENCES}

Allan, P. L., Baxter, G. M., and Weston, M. J. (eds) (2011). Clinical Ultrasound, 2-Volume, 715-716.

Bernirschke, K., Henderso, J. R., and Sweeny, J. C. (1984). "A vaginal mass, containing fetal bones in a common dolphin, Delphinus delphis," in Report of the International Whaling Commission (Special Issue 6), eds W. L. Perrin, R. L. Brownell, and D. P. DeMaster (Cambridge, UK: International Whaling Commission), 457-458.

Boyd, I. L., Lockyer, C., and Marsh, H. D. (1999). Reproduction in marine mammals. Biol. Mar. Mam. 266.

\section{ETHICS STATEMENT}

Ethical review and approval was not required for the animal study because this work comes from the exploitation of dead stranded animals.

\section{AUTHOR CONTRIBUTIONS}

WD: French stranding network manager who discovered most of the vaginal stones in stranded common dolphin necropsy. BR: technician student, who participated in calculi analysis during an internship. MD: doctor of the Necker Hospital, specialty of vaginal stones in women. VR: observatory director and article supervisor. All authors contributed to the article and approved the submitted version.

\section{FUNDING}

This research was funded by Ministère de la Transition Ecologique (MTE), Office Français de la Biodiversité and the EU project BIOCET (EVK3-2000-0027).

\section{ACKNOWLEDGMENTS}

We wish to pay tribute to late Dr. Raymond Duguy, founder of the national stranding scheme, who initiated the systematic biological examination of stranded marine mammals in France. Among many other scientific topics of interest to him, he greatly contributed to the initial collection of samples and information related to these vaginal stones in common dolphins. We are mostly grateful to all interns and members of staff of Observatoire PELAGIS, Cécile Delcroix, Ghislain Doremus, Jérôme Spitz, Olivier Van Canneyt, Fabien Demaret, Cécile Dars and all the field correspondents of the French stranding scheme for their assistance in collecting stranding data and associated biological material. We wish also to warmly thank Valérie Thiéry, Biochemistry Department, University of La Rochelle for her help in laboratory analyses and all BIOCET partners for their useful comments and fruitful discussions. This is a contribution to the Excellence Chair ECOMM funded by the Region Nouvelle Aquitaine.

Collet, A., and Harrison, R. J. (1981). Ovarian characteristics, corpora lutea and corpora albicanta in Delphinus delphis stranded on the Atlantic coast of France. Aquat. Mamm. 8, 69-76.

Dabin, W., Cossais, F., Pierce, G. J., and Ridoux, V. (2008). Do ovarian scars persist with age in all Cetaceans: new insight from the short-beaked common dolphin (Delphinus delphis Linnaeus, 1758). Mar. Biol. 156, 127-139. doi: 10.1007/s00227-008-1070-4

Essapian, F. S. (1961). Courtship in captive saddle-backed porpoises, Delphinus delphis, L. 1758. Z. Säugetiere. 27. 211-217.

Gurevich, V. S., Stewart, L. H., and Cornell, L. H. (1980). "The use of tetracycline in age determination of common dolphin, Delphinus delphis," in 
Age Determination of Toothed Whales and Sirenians. Rep Int Whaling Comm Spec Issue 3, eds W. F. Perrin, and A. C. Jr Myrick, Cambridge, 165-169.

Harrison, R. S. (1969). "Reproduction and reproductive organs," in The Biology of Marine Mammals, ed. H. T. Andersen (Hrsg.) (New York, NY: Academic Press), 253-342.

Hildebrand, M. (1987). "Composition chimique de calculs vaginaux chez le dauphin Delphinus delphis" in Thèse Pour le Diplôme d'état de Docteur Vétérinaire, Faculté de Médecine Vétérinaire de Hanovre. 100.

Hohn, A. A., and Fernandez, S. (1999). Bias in dolphin age structure due to age estimation technique. Mar. Mam. Sci. 15, 1124-1132.

Jauniaux, T., Beans, C., and Dabin, W. (2005). "Stranding, necropsy and sampling: collection data, sampling level and techniques," in Student ECS Workshop, 19th annual conference of the European Cetacean Society, La Rochelle, 2005.

Klevezal, G. A. (1996). Recording Structure of Mammals: Determination of Age and Reconstructing of Life History. Rotterdam: CRC Press/Balkema.

Kuiken, T., and Hartmann, M. G. (1991). "Dissection techniques and tissue sampling. European Cetacean Society Newsletter, 17 (special issue)," in Proceeding of the First ECS Workshop on Ceacean Pathology. Leiden, the Netherlands, 13-14 September 1991 (Stralsund: European Cetacean Society).

Kuzmanovski, I., Trpkovska, M., Šoptrajanov, B., and Viktor Stefov, V. (2003). Determination of the composition of human urinary calculi composed of whewellite, weddellite and carbonate apatite using artificial neural networks. Anal. Chim. Acta 491, 211-218. doi: 10.1016/s0003-2670(03)00787-6

Lee, R. A., Symmonds, R. E., and Williams, T. J. (1988). Current status of genitourinary fistula. Obstet. Gynecol. 72:313.

Lockyer, C. (1995). A review of factors involved in zonation in odontocete teeth, and an investigation of the likely impact of environmental factors and major life events on harbour porpoise tooth structure. Rep. Int. Commn. 511-529.

Martoja, R., and Martoja, M. (1967). Initiation aux Techniques de l'Histologie Animale Masson et Cie.

Maurice-Estepa, L., Levillain, P., Lacour, B., and Daudon, M. (2000). Advantage of zero-crossing-point first-derivative spectrophotometry for the quantification of calcium oxalate crystalline phases by infrared spectrophotometry. Clin. Chim. Acta 298, 1-11. doi: 10.1016/s0009-8981(00)00224-2

McFee, W. E., and Osborne, C. A. (2004). Struvite calculus in the vagina of a bottlenose dolphin (Tursiops truncatus). J.Wildl.Dis. 40, 125-128. doi: 10.7589/ 0090-3558-40.1.125
Oguzkurt, P., Ince, E., Ezer, S. S., Temiz, A., Demir, S., and Hicsonmez, A. (2009). Primary vaginal calculus secondary to urethrovaginal fistula with imperforate hymen in a 6-year-old girl. J. Pediatr. Surg. 44, e11-e13.

Perrin, W. F., and Donovan, G. P. (1984). Report of the Workshop. Reproduction in Whales, Dolphins and Porpoises. Cambridge, MA: International Whaling Commision, 1984.

Perrin, W. F., and Myrick, A. C. Jr. (eds) (1980). Age Determination of Toothed Whales and Sirenians. Rep. Int. Whal. Commn. Special Issue 3. 218.

Raghavaiah, N. V., and Devi, I. (1980). Primary vaginal stones. J. Urol. 123, 771-772. doi: 10.1016/s0022-5347(17)56126-1

Sawyer, J. E., and Walker, W. A. (1977). Vaginal calculus in the dolphin. J. Wildl. Dis. 13, 346-348. doi: 10.7589/0090-3558-13.4.346

Singhal, S., Nanda, S., and Singhal, S. (2007). Sexual intercourse: an unusual cause of vesicovaginal fistula. Int. Urogynecol. J. Pelvic Floor Dysfunct. 18, 587-588. doi: 10.1007/s00192-006-0171-1

Van Bressem, M.-F., Van Waerebeek, K., Siebert, U., Wünschmann, A., ChávezLisambart, L., and Reyes, J. C. (2000). Genital diseases in the peruvian dusky dolphin (Lagenorhynchus obscurus). J. Comp. Path. 122, 226-227. doi: 10.1053/ jcpa.1999.0369

Warner, M. R., Warner, R. L., and Clinton, C. W. (1979). Reproductive tract calculi, their induction, age incidence, composition and biological effects in Balb/c Crgl mice injected as newsborns with Estradiol-17ß. Biol. Reprod. 20, 310-322. doi: 10.1095/biolreprod20.2.310

Woodhouse, C. D., and Rennie, I. I. I. C. J. (1991). Observations of vaginal calculi in dolphins. J. Wildl. Dis. 27, 421-427. doi: 10.7589/0090-3558-27.3.421

Conflict of Interest: The authors declare that the research was conducted in the absence of any commercial or financial relationships that could be construed as a potential conflict of interest.

Copyright (c) 2021 Dabin, Rochowski, Daudon and Ridoux. This is an open-access article distributed under the terms of the Creative Commons Attribution License (CC BY). The use, distribution or reproduction in other forums is permitted, provided the original author(s) and the copyright owner(s) are credited and that the original publication in this journal is cited, in accordance with accepted academic practice. No use, distribution or reproduction is permitted which does not comply with these terms. 